\title{
Para além da forma, trabalhar o conteúdo
}

\author{
Juliana Winkel \\ Jornalista, especialista em Gestão da Comunicação, mestranda em Cîencias da Comunicação $e$ \\ editora executiva da revista Comunicação Ẽ Educação. \\ E-mail: juli.santos@usp.br
}

\begin{abstract}
Resumo: Gianna Cappello, presidente da Associazione Italiana per l'Educazione ai Media e alla Comunicazione (MED), fala sobre o aumento geral do interesse pela Media Education no mundo - e sobre as prioridades que os profissionais envolvidos com os campos da Comunicação e da Educação devem ter em mente nesses novos tempos, ao trabalhar com seu público.
\end{abstract}

Palavras-chave: Media education, comunicação, educação, Itália.
Abstract: Gianna Cappello, President of the Italian Association of Education for Media and Communication (Associazione Italiana per l'Educazione ai Media e alla Comunicazione (MED)), talks about the increasing general interest in Media Education in the world - and about the priorities that the professionals involved in the fields of Communication and Education should have in mind nowadays when working with the public.

Keywords: Media Education, Communication, Education, Italy.

No ano de 2011, a Summer School of Media Education - evento realizado anualmente pela Associazione Italiana per l'Educazione ai Media e alla Comunicazione (MED), organização que reúne educadores e comunicadores por toda a Itália - completou 20 anos de existência. A data foi comemorada com a escolha, para tema do evento, do cinema e da experiência narrativa como poderosas ferramentas de comunicação contemporânea. As discussões a respeito da Media Education - definida pela associação como "uma atividade educativa e didática voltada a desenvolver nos jovens a informação e compreensão crítica acerca da natureza e da categoria dos meios, assim como das técnicas por eles empregadas para construir mensagens e produzir sentido, em gêneros e linguagens específicas - foram, porém, além: abordaram os diversos aspectos do desenvolvimento humano e educacional no mundo, o aumento do interesse de governos e da iniciativa privada pela interface entre comunicação e educação e quais os riscos e vantagens que isso representa para alunos, mestres e profissionais. Na entrevista a seguir, a presidente da MED, Gianna Capello, fala a respeito da realidade vivida por esses dois campos hoje, assim como sobre a importância dos

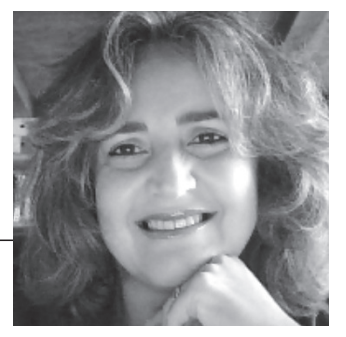


comunicação \& educação • Ano XVII • número 2 • jul/dez 2012

profissionais na condução da discussão crítica a respeito, sem se deixar levar pelo seu uso puramente instrumental.

C\&E: A Summer School of Media Education é um evento realizado há vinte anos, desde quando pouco se ouvia falar em mídias na escola, ao menos de maneira formal. O que mudou desde o início da realização do evento?

Uma das principais mudanças foi o perfil do público. Ano após ano, cresce a presença de educadores que não são, necessariamente, professores. Temos cada vez mais pessoas que trabalham com educação em projetos fora da escola, ou seja, são educadores da comunidade. Isso é uma coisa nova, porque inicialmente o MED teve, como sua vocação inicial, aquilo que é desenvolvido no mundo da escola. Com o passar dos anos, nos demos conta de que isso era importante, mas era ao mesmo tempo um grande limite. E que deveríamos, de alguma forma, integrar às nossas atividades esse grande âmbito de ação educativa que é a comunidade. Essa foi seguramente uma evolução.

Outra novidade provocada por nós nos últimos três ou quatro anos, ou seja, muito recentemente, foram os seminários metodológicos dentro do evento, acompanhando os laboratórios de produção. Os seminários foram criados a partir da necessidade de desenvolvimento também das competências do método. Servem não apenas - o que já é uma grande coisa - para aprender como se faz um vídeo, ou como se faz a análise de um filme, mas para imaginar como inserir a atividade de fazer um vídeo ou de analisar um filme na intenção da atividade educativa, seja didática, seja da educação não formal. Percebemos como é importante o desenvolvimento das metacompetências que dizem respeito ao método. Na verdade, esse foi um caminho natural, pois, à medida que nossa Media Education foi amadurecendo - depois do primeiro entusiasmo, de nos apropriarmos da tecnologia e percebermos as coisas que poderíamos fazer -, vimos, conversando com os educadores e com os cursistas, que era necessário desenvolver o método. Os participantes do evento diziam "É ótimo fazer um laboratório, mas, quando eu tiver que reproduzir isso em classe, na escola, como faço?". Os seminários metodológicos que introduzimos nos últimos anos são, também, um importante complemento nessa formação.

C\&E: Você acredita que o aumento do interesse pela educação não formal reflete um movimento presente no país, dentro da Media Education?

Certamente. A escola permanece ainda o âmbito mais recorrente, ou ao menos o mais documentado, das experiências em Media Education. É mais fácil ter acesso às ações, mesmo às pesquisas, e mensurar o desenvolvimento e a difusão dessas atividades na escola, pelo seu próprio caráter institucional. É possível ir até lá e fazer as pesquisas que permitirão entender o que se está fazendo e de que modo. A comunidade, sob esse ponto de vista, é muito mais emergente. As pessoas que trabalham na comunidade, geralmente, não possuem competência nem sentem a necessidade de documentar e valorar aquilo que fazem. Dessa forma, normalmente não permanecem os traços do seu trabalho. 
Os professores, por sua vez, devem documentar de alguma forma suas atividades. A minha impressão, e que também é uma hipótese a ser pesquisada, é de que talvez tenhamos tendência a pensar que na escola se faça mais Media Education porque temos mais documentação. Para nós, a escola, por definição, é um território de experimentação. Na Itália, essa experimentação é promovida pelo próprio Ministério, o que faz com que os professores tenham maior autonomia para introduzir novas atividades. Mas estou segura de que essa efervescência, digamos, existe também na comunidade. Não temos os registros porque é mais difícil ir a campo e ver o que estão fazendo. Dessa forma, cabe a nós procurar conhecê-la para realizar coisas em conjunto. Por isso, fico contente em ver que este ano tivemos um número significativo de pessoas que vêm da comunidade.

C\&E: Quais são os principais desafios hoje, na Itália, para a Media Education?

Por muito tempo, pensamos que a coisa mais importante fosse buscar uma legitimação interna na escola. A figura do Media Educator, ou ao menos as atividades de Media Education, deveriam ser reconhecidas de algum modo, inseridas de forma mais ou menos oficial no currículo escolar - de modo que os professores responsáveis por essas atividades não se sentissem "os estranhos", os que fazem coisas diferentes, os que perdem tempo e não ensinam coisas realmente sérias. Por muito tempo, achamos que esse era o horizonte.

Porém, o que estamos vendo, nos últimos dez ou quinze anos, é a expansão do interesse pelas novas tecnologias. Na Itália, as novas mídias finalmente entraram na escola de forma oficial, apoiadas pelo Ministério, que fornece fundos para os laboratórios de informática e tudo mais. Claro que nos sentimos um pouco adulados por isso. É um interesse muito positivo, mas não nos podemos esquecer de que existe um risco sob esse fenômeno, que é o da visão puramente instrumental. O Governo, o Ministério, o setor público, finalmente prestaram atenção nas mídias e nas novas tecnologias, mas o fazem com uma visão extremamente reducionista. Os meios são simplesmente os instrumentos - ou seja, toda a dimensão crítica, criativa, de empenho social, digamos, da educação para a cidadania, que é a coisa mais importante desse processo, corre o risco de passar para segundo plano. Então, por um lado podemos dizer que nosso desejo de legitimação da presença da mídia na escola está se realizando. Por outro lado, devemos nos perguntar: "Mas estamos realmente satisfeitos com a forma como está se realizando?”.

C\&E: E sobre o crescimento da Media Education no mundo, o que você acha? $O$ que significa o aumento do interesse pela comunicação e educação em tantos países?

Nós vivemos um momento que, por um lado, é de grande potencial, de grande esperança e de grande futuro. Porém, por outro lado, essa mesma expansão da mídia digital produz grandes riscos, que são os de diluir, "edulcorar" a 
comunicação \& educação • Ano XVII • número 2 • jul/dez 2012

força socialmente transformadora da Media Education, reduzindo-a à capacidade de se saber usar um computador e um mouse.

O verdadeiro desafio que devemos procurar levar avante - nós que nos ocupamos dessa área já há vinte ou trinta anos, quando ainda se falava apenas de televisão, cinema, rádio e jornal impresso - é o de não se deixar enganar por esse interesse mundial, porque, indubitavelmente, ele existe em todo o mundo. Em todos os lugares se vê essa febre de experimentação, esse interesse, essa atenção renovada. Mas talvez essa atenção crescente seja puramente superficial - mais superficial, inclusive, do que aquilo que as mídias digitais têm a capacidade de trazer para a escola até mesmo como instrumento. É como se olhassem para uma bela garota e prestassem atenção somente à sua beleza, mas não ao conteúdo que ela tem a oferecer.

Para alcançar esse objetivo de aprofundamento, diria que é preciso ter em mente duas coisas: a importância de unir sempre a teoria e a prática, deixando que as duas se nutram mutuamente; e tornar mais possíveis - e é aquilo que procuramos fazer também enquanto associação - os projetos de pesquisa. Devemos fazer isso de modo aplicativo, trabalhando no campo, seja na escola ou na comunidade. Ligada a estas ações está a necessidade de estudar as práticas sempre mais, com rigor científico sempre maior. Já que há muitas práticas no campo e, talvez, e graças à rápida expansão da mídia digital, a resistência dos educadores às atividades com a mídia tem diminuído, temos a necessidade de estudar essas práticas com atenção e rigor científico. É importante documentá-las, valorá-las e classificá-las, para descobrir o que funciona e o que não funciona - porque, às vezes, as coisas que não funcionam trazem mais danos do que se não fossem feitas. Em alguns casos, é preferível que o professor continue a fazer sua aula da maneira tradicional do que pensar em fazer coisas novas e experimentais que depois se traduzam em perda de tempo - justificando as críticas daqueles que estão sempre prontos a dizer: "Viu, você perde tempo ao fazer essas coisas, sem alcançar resultado". Então, devemos nos prontificar a valorar essas práticas e criar modelos possíveis de referência, inclusive para multiplicá-las e difundi-las mais tarde.

C\&E: Você acha que essa preocupação se tornará também um interesse difundido ao redor do mundo?

O movimento, por si só, de interesse pela Media Education e pelo uso da mídia no contexto educativo, da escola e do território, existe. E é quase natural, no sentido de refletir a expansão das mídias. Difundindo as mídias de forma permissiva, porém, os educadores não podem afrontar de forma adequada isso junto a seu público. Nosso desafio para o futuro é que a Media Education seja conhecida e usada em profundidade. Creio que atualmente, e sempre mais no futuro, a questão principal será entender o que fazer e como fazer. Há vinte anos, nosso problema era o fato de muitos professores não terem sequer $o$ hábito de ler o jornal em sala de aula. $\mathrm{O}$ objetivo, portanto, era promover o uso da mídia na escola. Hoje não nos preocupamos mais com isso, porque essa 
promoção é feita pelo Ministério. Usar a mídia na escola se tornou quase um imperativo categórico. Então, nesse momento, temos outros desafios, talvez mais importantes que o primeiro: a formação dos professores e a documentação e valoração científica daquilo que os educadores da comunidade fazem.

Essa necessidade será sempre maior, inclusive no Brasil, porque o país está crescendo e logo o próprio Governo se dará conta de que, se quiser formar cidadãos verdadeiramente digitais, também terá de se envolver com essa questão, a partir das próprias escolas públicas. Acredito que, com o tempo, os desafios enfrentados pelos profissionais envolvidos com comunicação e educação começarão a se aproximar - o que contribuirá, também, para a aproximação entre os países e a troca de experiências e informações sobre o que é feito ao redor do mundo, algo que é sempre positivo. 


\section{MUITO ALÉMDEUMA LOUSAEPEDACOS DE GIZ}

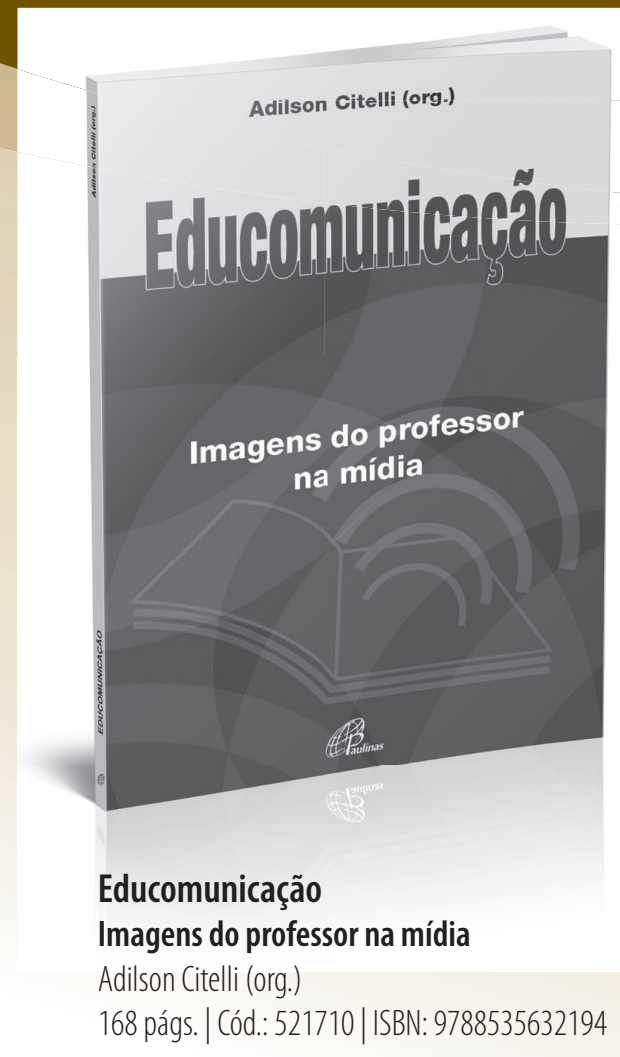

\section{Como as mídias propagam \\ as imagens dos professores}

Quem dera os problemas dos professores fossem somente os apresentados aos alunos em sala de aula. Os professores do Ensino Básico enfrentam muitas outras dificuldades. Salários muito baixos, materiais de péssima qualidade, precariedade nos equipamentos e estruturas da sala de aula, jornadas exaustivas, entre outras complicações. Problemas que realmente precisam de solução. Mas será que as mídias mostram a realidade desses professores?

Pensando nessa questão, oito pesquisadores, entre mestrandos e doutorandos da Escola de Comunicações e Artes da Universidade de São Paulo (ECA-USP), se reuniram, sob a orientação do professor dr. Adilson Citelli, para debater o tema. Os autores utilizaram um método crítico-analítico para mostrar como a televisão, o rádio, o jornal, o cinema e até mesmo a publicidade apresentam os professores, com ou sem referências da realidade dessa categoria no Brasil.

\section{$\bowtie \infty<\infty<\infty<\infty<\infty$ Leia também os outros livros da coleção Educomunicação}

$\infty<\infty<\infty<\infty<\infty<\infty$

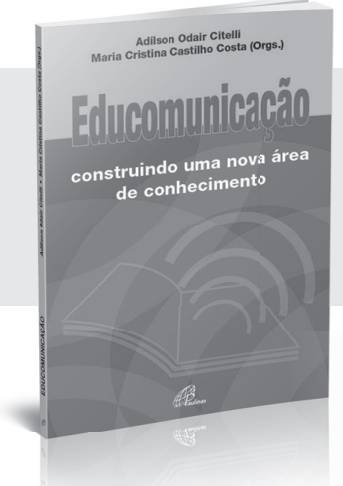

\section{Educomunicação \\ Construindo uma nova área de conhecimento \\ Adilson Odair Citelli e Maria Cristina Castilho Costa (orgs.) \\ 256 págs. Cód. 518239 | ISBN: 9788535627466}

Educomunicação

0 conceito, o profissional, a aplicação

Contribuições para a reforma do Ensino Médio

Ismar de Oliveira Soares

104 págs. | Cód.: 518298 | ISBN: 9788535627527 